\title{
Iniciação à docência em Física e as indagações de estudantes da educação básica - um relato
}

\author{
Pedro Donizete Colombo Junior ${ }^{1}$ iD, Daniel Fernando Bovolenta Ovigli ${ }^{2}$ iD, Sabrina Eleutério Alves ${ }^{3}$
}

Resumo: Atividades extensionistas que visem propiciar a educação em ciências são cada vez mais presentes em discussões educacionais, sejam como forma de pensar novas roupagens para conteúdos programáticos ou para novos vieses metodológicos e de avaliação dos processos educativos. Este trabalho apresenta e discute a atividade "Pílula da ciência: o conhecimento está no ar!", desenvolvida no âmbito do Programa Institucional de Bolsas de Iniciação à Docência (PIBID/CAPES), junto a uma escola pública de Uberaba/MG, em parceria com o grupo PIBID-Física-UFTM, com ênfase em suas contribuições à formação dos envolvidos, licenciandos em Física. O objetivo da atividade desenvolvida foi promover uma dinâmica que permitisse, por um lado, ouvir as inquietações e indagações dos estudantes da Educação Básica frente às suas dúvidas em relação ao conhecimento científico e, por outro lado, proporcionar novas vivências em sala de aula por parte de pibidianos, professores em formação. Para tanto, estudantes da Educação Básica depositavam questionamentos (aqui denominados pílulas) sobre temas voltados às Ciências da Natureza em uma caixa de dúvidas, para posterior socialização das respostas em sala de aula com os pibidianos. Evidenciamos que ouvir e discutir as percepções dos estudantes frente à visão que estes têm do conhecimento científico é um caminho promissor para despertar seu interesse pela ciência, sendo os primeiros passos para o letramento científico, além de ser uma estratégia para sensibilizar os futuros professores a considerarem estas abordagens em suas futuras práticas pedagógicas.

Palavras-chave: Ensino de Física; Iniciação à docência; Estratégias didáticas

\section{Physics teaching initiation and the students' questions in basic education - a report}

\begin{abstract}
Extension activities that aim to provide science education are increasingly present in educational discussions, whether as a way of thinking about new approaches for curricular contents or new methodological biases and evaluation. This paper presents and discusses the activity "Pill of science: the knowledge is in the air!" developed under the Institutional Program of Initiation to Teaching Scholarship (PIBID/CAPES), at a public school in Uberaba, Brazil, in partnership with the PIBID-Physics-UFTM group, with an emphasis on their contributions to the training of those involved, undergraduates in Physics. The objective of the activity developed was to promote a dynamic that would allow, on the one hand, to listen to the concerns and questions of Basic Education students in the face of their doubts regarding scientific knowledge and, on the other hand, to provide new experiences in the classroom by teachers in training. To this end, Basic Education students deposited questions (here called "pills") about topics related to the Natural Sciences in a box of doubts, for later socialization in the classroom with the undergraduates in Physics. We show that listening and discussing students' perceptions of their view of scientific knowledge is a promising way to awaken their interest in science, being the first steps towards scientific literacy, in addition to being a strategy to sensitize future teachers to consider these approaches in their future pedagogical practices.
\end{abstract}

Keywords: Physics Teaching; Teaching Initiation; Didactic Strategies
Originais recebidos em

08 de julho de 2020

Aceito para publicação em

01 de setembro de 2020

1

Professor da Universidade Federal do Triângulo Mineiro (UFTM). Doutor em Ensino de Física pela Universidade de São Paulo (USP).

pedro.colombo@uftm.edu.br (autor para correspondência)

2

Professor da Universidade Federal do Triângulo Mineiro (UFTM). Doutor em Educação para a Ciência pela Universidade Estadual Paulista "Júlio de Mesquita Filho" (Unesp).

daniel.ovigli@uftm.edu.br

3

Professora da Educação Básica do Estado de Minas Gerais. Mestra em Ensino de Ciências e Matemática pela Universidade Federal de Uberlândia (UFU).

binaeleuterio@hotmail.com 


\section{Introdução}

Pensar abordagens inovadoras na educação em ciências, em especial na Educação Básica, está cada vez mais presente em discussões no cenário educacional, fato observado em diversas pesquisas (Arruda \& Caetano, 2012; Alffonso, 2019). Como pontuam Arruda e Caetano (2012, p. 114), "a escola, como fonte de informação e conhecimento, precisa promover a inovação, renovando os ambientes de forma que esses possam propiciar a criatividade e o desenvolvimento da imaginação". A partir da Lei de Diretrizes e Bases da Educação Nacional (LDB 9394/96) derivaram propostas curriculares que destacam a necessária discussão de temas contextualizados e interdisciplinares, de modo a permitir a aproximação do cotidiano com o ambiente escolar do estudante (Arruda et al., 2013; Taxini et al., 2012). Em particular na educação em ciências, muitos são os desafios que se colocam frente aos processos de ensino-aprendizagem (Ferreira et al., 2019; Braga \& Martins, 2019), considerando a complexidade na abordagem de determinados temas, e a necessidade dos trabalhos experimentais e investigativos como forma de compreensão do desenvolvimento científico, em constante atualização (Campos et al., 2012; Zompero et al., 2017; Solino \& Sasseron, 2019).

Tais fatores remetem a pensar o ensino para além da compartimentalização de um currículo estanque, que demora a incorporar os avanços científicos e tecnológicos. Frente a este cenário é crescente o número de projetos educacionais com perspectivas pedagógicas inovadoras e dialógicas, de caráter extensionista, e que têm como foco as salas de aulas da Educação Básica (Ustra et al., 2014; Vieira \& Sabbatini, 2017; Dias et al., 2018; Dorigo et al., 2020). A matriz teórica de desenvolvimento destas ações repousa em diferentes frentes que refletem sobre a educação no espaço da diversidade, da sustentabilidade e da inclusão (Araújo \& Pedrosa, 2014; Oliveira \& Benite, 2015; Fernandes et al., 2016; Silva \& Bego, 2018), e que reclamam por maior interação entre a escola e seus diferentes atores. Nesse sentido, a inovação trazida por práticas extensionistas, sejam elas de natureza curricular, metodológica ou avaliativa, tem sido uma tendência, quando se pensa em aproximar o mundo vivencial do estudante da ciência escolar (Arruda et al., 2013; Gonçalves et al., 2015; Vieira \& Sabbatini, 2017).

Nesse cenário de necessária indissociabilidade entre diferentes instâncias formativas (ensino, pesquisa e extensão), destaca-se o Programa Institucional de Bolsas de Iniciação à Docência (PIBID/CAPES), o qual propicia o desenvolvimento de uma miríade de propostas de intervenção no cotidiano escolar, a partir da integração Universidade-Escola (Correia, 2016; Oliveira \& Algebaile, 2019; Dorigo et al., 2020). Extensão universitária pode ser entendida como uma ação efetiva da Universidade junto à comunidade, de forma a compartilhar experiências oriundas de suas vertentes de ensino e de pesquisa. Comungamos da ideia de que extensão universitária é uma via de mão dupla, na qual os conhecimentos são compartilhados e democratizados. Ou, como explicitado durante o I Encontro de Pró-Reitores de Extensão das Universidades Públicas Brasileiras, "a extensão universitária é o processo educativo, cultural e científico que articula o ensino e a pesquisa de forma indissociável e viabiliza a relação transformadora entre a Universidade e a sociedade" (Fórum de Pró-Reitores de Extensão das Universidades Públicas Brasileiras [FORPROEX], 1987).

Compartilhamos com outros autores (Trindade et al., 2013; Fernandes et al., 2014) de que o PIBID pode ser entendido como um programa de extensão universitária com um forte apelo no ensino, haja vista sua estruturação sustentada pela melhoria da formação inicial de professores. Desta forma, entendemos a ocorrência da indissociabilidade entre ensino, pesquisa e extensão nas ações desenvolvidas pelo PIBID, ou seja, ao mesmo tempo que aproxima a Universidade da escola, leva a ela novos conhecimentos oriundos de suas pesquisas acadêmicas, e também contribui com a formação inicial de professores, ao propiciar novas vivências para os licenciandos, ainda no momento de sua formação inicial. Como mencionam Fernandes et al. (2014, p. 2), "O PIBID se destaca como ponte para extensão universitária, propiciando um contato direto entre 
educadores e estudantes das escolas públicas, aproximando a universidade de toda a comunidade escolar e abrindo, desta forma, perspectivas mais promissoras de qualificação profissional a todos os partícipes do Programa".

No bojo destas propostas está o subprojeto PIBID-Física da Universidade Federal do Triângulo Mineiro (UFTM), o qual vem promovendo esse diálogo na cidade de Uberaba, Minas Gerais, com foco na melhoria da Educação Básica, em especial no ensino de Física, com contornos especialmente voltados para as inovações educacionais em âmbito metodológico (Fragelli \& Mendes, 2012; Ustra et al., 2014; Gonçalves et al., 2015). Dentre tais inovações, podemos citar a introdução de metodologias ativas no ensino de Física, como Kahoot! e Instrução por Pares (Peer Instrucion) (Watkins \& Mazur, 2010), o ensino por investigação (Colombo Junior et al., 2020) e o uso de charges, histórias em quadrinhos (HQ) e tirinhas no ensino de Física (Colombo Junior \& Ovigli, 2018).

É nesse contexto que atividades de matriz extensionista propostas pelo subprojeto PIBID-Física da UFTM apresentam-se como contributos dialógicos para uma efetiva interação Universidade-Educação Básica. Esse movimento dialógico caracteriza-se como meio para a democratização do conhecimento, bem como para uma participação da comunidade na universidade, e vice-versa (FORPROEX, 2012), e é a partir desse pressuposto que compreendemos a ação que é objeto deste artigo.

Dessa forma, para que a aproximação do saber científico escolar com o cotidiano do estudante faça sentido, torna-se de fundamental importância ouvi-lo, incluir suas concepções prévias, anseios e angústias frente aos processos formativos, aspectos estes necessários também no trabalho da formação inicial de professores, particularmente da área de Física. Neste texto socializamos a atividade intitulada "Pílula da ciência: 0 conhecimento está no ar!', desenvolvida em uma escola pública da cidade de Uberaba/MG, dentro das ações interventivas propostas pelo PIBID-Física da UFTM, em um movimento de parceria com a escola, tendo como agente mobilizador as expectativas e inquietações que emergem dos estudantes sobre temas científicos, em especial os relacionados ao ensino de Física e Astronomia. O termo figurativo "Pílula da ciência" traz implícita a ideia de debater temas específicos da ciência (em doses de conhecimentos) que derivam da curiosidade e do interesse dos estudantes.

Dentre as justificativas que sustentaram essa ação, encontra-se a necessidade e a importância em ouvir o jovem e trabalhar tópicos de ciências a partir de seus interesses e suas inquietações (Ustra et al., 2014; Gonçalves et al., 2015; Dias et al., 2018). Para Pereira et al. (2015), a inovação sob o olhar da escola não consiste exclusivamente em mudanças curriculares, mas também se pauta em novas formas e novos procedimentos que possibilitem facilitar o processo de ensino e aprendizagem, incluindo materiais didáticos, produtos educacionais, ideias e diferentes abordagens de ensino.

Concordamos com Pietrocola (2005), para quem a Física como conhecimento só poderá ser integrada ao patrimônio intelectual dos indivíduos caso possa ser percebida em relação ao mundo que os cerca. O PIBIDFísica da UFTM, em particular, conta com objetivos que visam atender a essa realidade. Assim, buscamos discutir o desenvolvimento da ação aqui relatada considerando, em especial, o processo formativo vivenciado pelos participantes.

\section{Desenho metodológico: contexto e participantes da atividade}

Na efetivação da atividade, adotamos uma abordagem colaborativa, com traços de pesquisa-ação (Azevedo \& Abib, 2013). Participaram seis pibidianos, licenciandos em Física junto à UFTM, a professora supervisora na escola pública, o professor coordenador do subprojeto e um colaborador externo, professor da UFTM, os quais trabalharam conjuntamente na elaboração, desenvolvimento, análise e devolutiva dos resultados das 
atividades realizadas, dentro do ciclo previsto na pesquisa-ação. Desenvolvida na Escola Estadual Francisco Cândido Xavier (EEFCX), parceira do PIBID-Física, e situada em uma região periférica da cidade, a instituição atende a aproximadamente 740 jovens matriculados no Ensino Médio.

A escola conta com laboratórios de ciências, de línguas e de informática, e oferecia infraestrutura com menos de três anos de uso, à época da intervenção. Seu Projeto Político-Pedagógico (PPP) e Regimento Escolar afirmam que a instituição busca constantes parcerias com instituições, a exemplo da UFTM, para o desenvolvimento de projetos, e a atividade em tela foi realizada neste cenário, ao decorrer do ano de 2017, contando com a disponibilidade e o apoio quanto à estrutura física e à gestão da escola.

Para suas ações, o "Pílula da ciência" consistiu, em primeiro momento, na disponibilização de um artefato (caixa de papelão) chamado de "Caixa de Dúvidas" (Figura 1) durante uma semana, a qual percorreu diferentes ambientes da escola, dentre eles quatro salas de aula do Ensino Médio, sendo três de $1^{\circ}$ ano e uma de $2^{\circ}$ ano, para que os estudantes depositassem suas inquietações e seus questionamentos relacionados às Ciências da Natureza, de modo a fomentar as ações seguintes da proposta. Juntamente com a caixa de dúvidas, confeccionou-se também um banner que facilitava a identificação da atividade, com o objetivo de aguçar a curiosidade dos jovens. Tal ação teve o intuito de levantar o maior número possível de questionamentos sobre as ciências em uma ação in loco, na qual não se tinha obrigatoriedade de participação.

Destaca-se que foram disponibilizadas folhas sulfite, em cores diferentes, para as turmas, sendo a cor amarela para $1^{\circ}$ ano e cor azul para o $2^{\circ}$ ano, de modo a identificar de qual partia a dúvida sem, contudo, identificar o participante. Este procedimento foi fundamental para guiar as ações futuras da professora, ou seja, direcionar as discussões em salas de aula do primeiro e segundo anos. Os estudantes do $3^{\circ}$ ano do Ensino Médio não participaram, visto que a professora supervisora do PIBID-Física não ministrava aulas para esta turma no momento de realização da atividade.

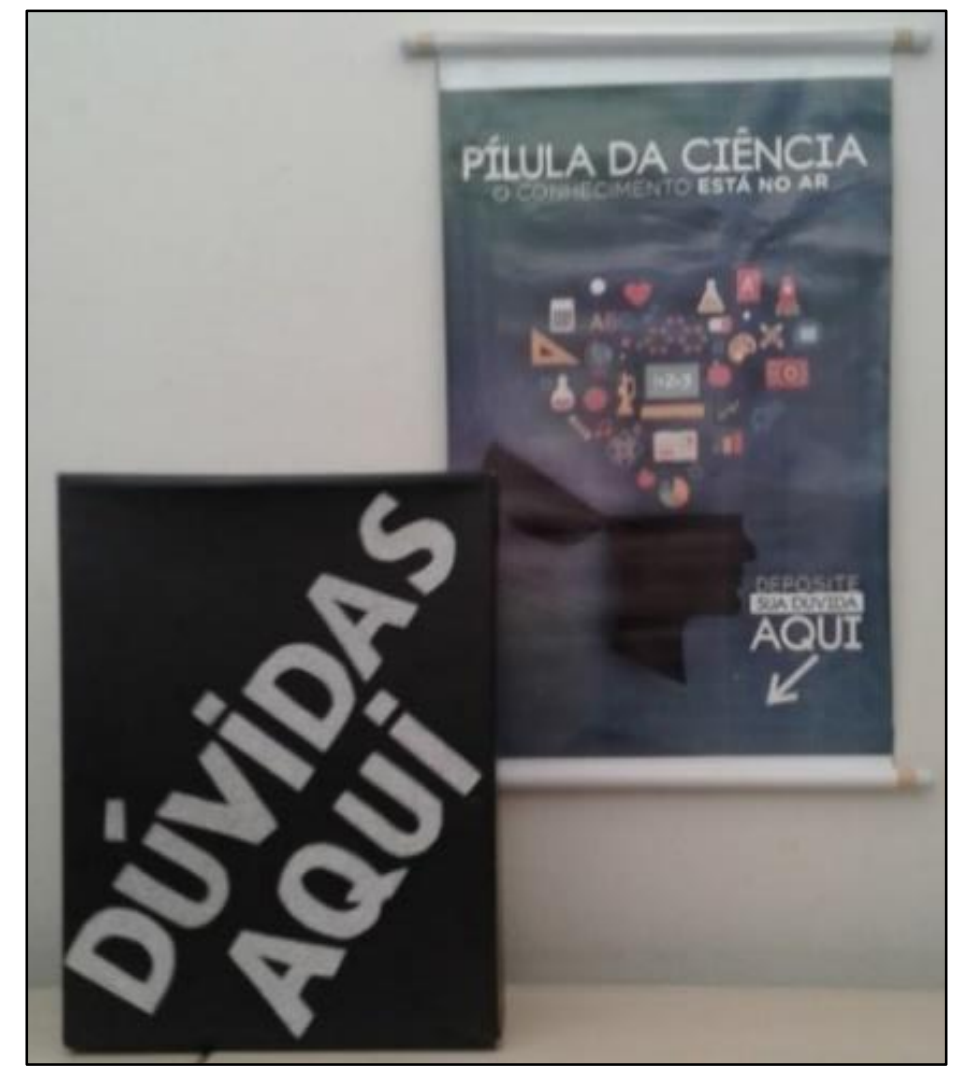

Figura 1. Caixa de Dúvidas para que os estudantes do Ensino Médio depositassem seus questionamentos. 
Fonte: dos autores.

Levantadas as indagações e inquietações, a professora supervisora, juntamente com os pibidianos, realizou a leitura inicial de todo o material depositado na Caixa de Dúvidas, de modo a organizar os questionamentos por afinidade temática. Os licenciandos, então, sob a supervisão da professora, prepararam aulas sobre as temáticas centrais e as trabalharam com as turmas, em aulas de intervenção por ela cedidas. Neste momento, fizeram o uso de diferentes recursos audiovisuais, a exemplo de filmes, charges e simuladores, desenvolvendo diferentes estratégias para trabalhar conteúdos de ciências/Física com os estudantes da Educação Básica. Dentre as estratégias utilizadas destacamos o ensino por meio da argumentação em sala de aula e a sala de aula invertida (flipped classroom) (Pessoa \& Costa, 2019). Durante as aulas, os alunos também foram indagados sobre o que para eles tornaria as aulas de Física mais atraentes.

A tentativa consistiu em aguçar o interesse dos jovens a participarem mais das aulas de Física, as quais muitas vezes são consideradas difíceis e desinteressantes (Fragelli \& Mendes, 2014; Gonçalves et al., 2015). Ademais, acentuar a curiosidade e as indagações dos estudantes, promovendo-as de curiosidade ingênua, munida muitas vezes do senso comum, para curiosidade epistemológica, mais aguçada cientificamente (Freire, 1996), coloca-se como postura que contribui para o caminhar em direção à formação cidadã e participativa. A curiosidade epistêmica pode ser percebida quando os estudantes se deparam com a oportunidade de questionarem a informação previamente recebida pelos mais diversos meios, como as mídias e os amigos. A Caixa de Dúvidas traduz, então, esta possibilidade de os alunos refletirem, em âmbito da escola, sobre algo que os inquieta, ou ainda, alinhados com as ideias de Freire (1996), exercer a capacidade crítica de aprender. Desenvolver trabalhos que destoem do convencional (tradicional), sobretudo com temáticas científicas, em sala de aula, pode representar uma inovação não apenas metodológica, mas também atitudinal do trabalho docente e da interação discente, além de ser uma postura emancipatória na prática do professor (Pereira et al., 2015; Correia, 2016; Braga \& Martins, 2019). Paralelamente à inovação promovida em sala de aula, o fato de os pibidianos terem a oportunidade de planejar e executar atividades dessa natureza mostra-se enriquecedor em sua trajetória formativa enquanto futuros professores.

A atividade contou com a participação de 90 jovens, perfazendo 82 perguntas levantadas, havendo pequeno número em duplicidade, ou seja, questionamentos iguais ou similares. Anteriormente à discussão das questões em aula, buscamos levantar os perfis dos estudantes, no intuito de melhor planejar as aulas que subsidiariam as discussões das dúvidas explicitadas. Neste momento de planejamento, no contexto da pesquisa-ação (Araújo \& Abib, 2013), buscamos construir um estofo que norteasse a construção de intervenções dialógicas, de modo a potencializar o processo de ensino e aprendizagem e proporcionar discussões com os envolvidos, indo ao encontro dos interesses por eles expressos. Para tanto, valemo-nos de um questionário que abarcava três âmbitos: (i) socioeducacional, (ii) convívio e (iii) ambiente escolar. Nossa referência consistiu no modelo utilizado pelo Exame Nacional do Ensino Médio (ENEM), já validado e utilizado neste exame aplicado em larga escala (disponível em Material Suplementar). Responderam a este questionário 125 alunos dos $1^{\circ}$ e $2^{\circ}$ anos do Ensino Médio (três salas de $1^{\circ}$ ano e uma sala de $2^{\circ}$ ano).

\section{Resultados e Discussão}

Considerando os objetivos deste texto, e para ilustrar nossos resultados, apresentamos as respostas dos estudantes sobre duas questões (n. 17 a 18, ver Material Suplementar) diretamente envolvidas com as discussões aqui traçadas. A primeira delas, para a qual era possível marcar mais de uma opção, refere-se à área de conhecimento que os estudantes preferem (Figura 2). 
$\%$

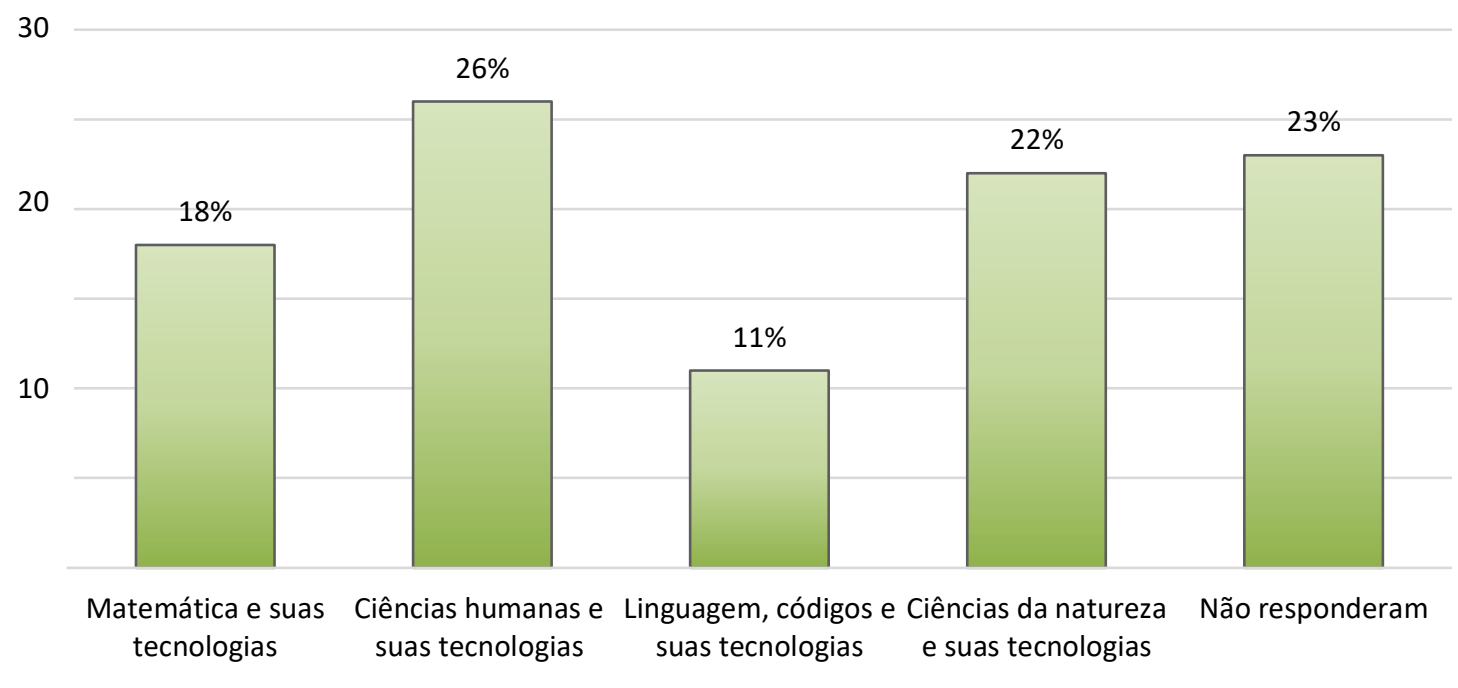

ÁREA DE CONHECIMENTO

Figura 2. Porcentagem de respostas frente à pergunta: "Qual a sua área de maior interesse?"

Fonte: dos autores.

Como resultado, as Ciências Humanas e suas Tecnologias tiveram destaque, seguida de Ciências da Natureza, Matemática e, por último, a área de Linguagens e Códigos. Vale ressaltar que $23 \%$ dos alunos não responderam a este questionamento (Figura 2). Esse fato levou os licenciandos a prepararem uma aula, ministrada para todos os anos, específica para apresentar e discutir a estruturação do ENEM e as suas áreas de conhecimento. Podemos perceber, ainda, um expressivo interesse pelas Ciências da Natureza, sendo um ponto de partida para desenvolver a atividade proposta.

Outro questionamento apresentado aos estudantes foi o que tornaria as aulas de Física mais atraentes. De acordo com a Figura 3, os itens que mais se destacaram foram (i) o uso de experimentos ( $86 \%$ das respostas) e (ii) a inclusão de visitas didáticas ( $83 \%$ das respostas).

Concluída esta etapa, a equipe passou a elaborar o plano de trabalho e as ações a serem desenvolvidas, adentrando ao segundo momento da pesquisa-ação (Araújo \& Abib, 2013), a qual foi realizada no decorrer do primeiro semestre de 2018, com a disponibilização da Caixa de Dúvidas, e a posterior tabulação das perguntas levantadas pelos jovens. A partir da exploração das respostas, foram delineados os seguintes grandes temas:

(i) Evolução Estelar: questões que abordam a sequência de mudanças pelas quais passa uma estrela durante seu 'tempo de vida';

(ii) Escalas de Distância em Astronomia: perguntas que tratam de aspectos relativos às distâncias existentes entre astros, dentro e fora do Sistema Solar;

(iii) Ondas e Ótica: congrega fenômenos da luz, envolvendo cor e a visão humana, bem como os fenômenos ondulatórios, especialmente propagação do som;

(iv) Planetas e seus movimentos: dúvidas relativas aos movimentos de planetas e sua relação com a existência do dia e da noite, estações do ano e eclipses, por exemplo;

(v) Epistemologia da ciência: envolve aspectos relacionados à história de cientistas, bem como as formas pelas quais se processa a construção do conhecimento científico (sua natureza);

(vi)Calor/Temperatura: fenômenos térmicos, como calor, temperatura, dilatação, energia térmica e estudo térmico dos gases. 


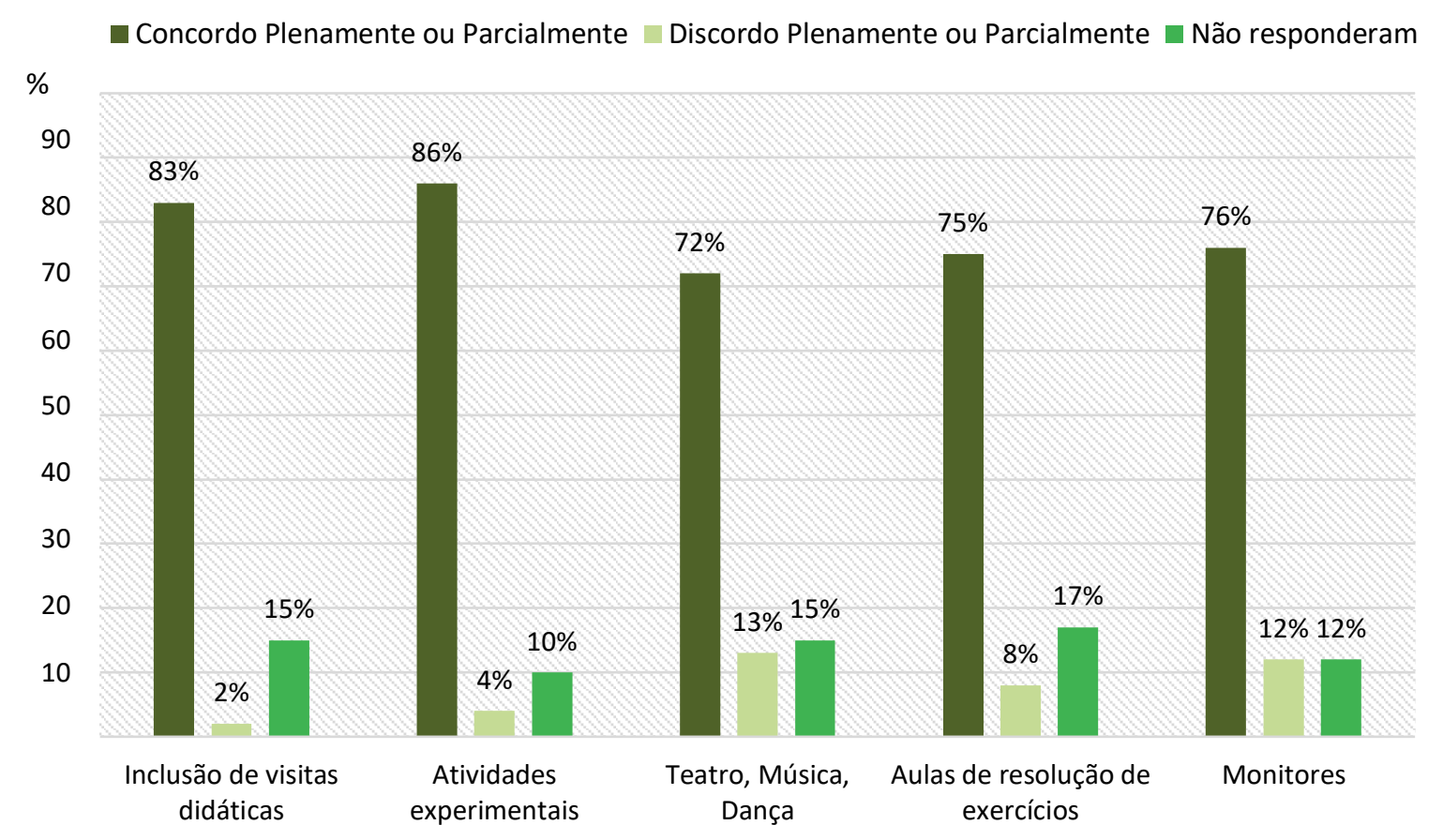

Figura 3. Concordância frente à pergunta "Em sua opinião, o que tornaria as aulas de Física mais atraentes?" Fonte: elaborado pelos autores.

A partir desta categorização, a equipe observou que os estudantes apresentaram muitos questionamentos relacionados a conceitos físicos e temas de Astronomia, com reduzido número relacionado à Química e à Biologia. O Quadro 1 exemplifica questionamentos, agrupados nos temas delineados, realizados pelos estudantes.

Inferimos que o grande número de questionamentos relacionados à temática de Astronomia se justifica em função das constantes informações divulgadas na mídia acerca desta ciência, o que pode indicar o poder que a mídia tem sobre a percepção dos alunos acerca de tópicos da ciência, para além de outras possibilidades de interpretação. Destaca-se que, antes das intervenções em sala de aula, os pibidianos destinaram momentos para estudar os conteúdos, aprofundando os conceitos nas áreas em que se desenvolveu alguma ação direcionada em sala de aula e solicitavam, quando necessário, apoio à supervisora e aos professores da universidade, tanto em explicações, quanto em sugestões para a construção das aulas, dentro da proposta colaborativa da pesquisa-ação. Essa etapa de construção das aulas, em conjunto, foi importante por contribuir com o processo de formação dos licenciandos, ao terem proximidade com as rotinas de planejamento e execução de atividades de um professor em exercício, como destacado em suas falas, evidenciando impactos em sua formação. Trata-se, também, da etapa avaliativa prevista na pesquisa-ação:

[...] ser professor sempre foi meu objetivo, por conta disso optei por um curso de licenciatura. $A$ proposta do PIBID de fazer com que alunos de graduação entrem de fato em salas de aulas se destaca pelo fato de que outros subprojetos não realizam essa proposta da mesma forma. Optando por aulas em contraturno os graduandos se veem em uma posição não tão realista quanto a que o subprojeto Física proporciona, pois trabalhamos em salas reais, onde não é possivel escolher para quais alunos daremos aula [...]. Entramos na faculdade pensando em ser o tipo de professor que todos respeitam ou sentem medo, porém vemos que isso nem sempre é bom, pois a força pode tornar os alunos desinteressados em sua matéria, independentemente do quão "divertida" ela se mostre, vemos então a importância de saber lidar com diversos tipos de alunos [...] (Pibidiano PHGM, grifos nossos). 
Quadro 1. Questionamentos feitos pelos alunos e respectivas categorias de análise

\begin{tabular}{|l|l|}
\hline \multicolumn{1}{|c|}{ Categorias } & \multicolumn{1}{|c|}{ Questionamentos Dos Alunos } \\
\hline Evolução Estelar & $\begin{array}{l}\text { Como se forma uma nebulosa? } \\
\text { Como se formou as estrelas? } \\
\text { Por que o Sol vai explodir? }\end{array}$ \\
\hline Escalas de Distâncias & $\begin{array}{l}\text { Podemos chegar em Marte? } \\
\text { Quantos anos-luz têm de distância da Terra ao Sol? } \\
\text { Alguém poderia chegar em uma estrela? }\end{array}$ \\
\hline Ondas e Ótica & $\begin{array}{l}\text { Como a música de um instrumento se mistura no ar? } \\
\text { Quais tipos de espécie de luz existem? }\end{array}$ \\
\hline Planetas e seus movimentos & $\begin{array}{l}\text { Como aconteceu as existências dos planetas? } \\
\text { Por que acontece o eclipse lunar e solar? } \\
\text { Por que existe dia e noite? } \\
\text { Por que o eclipse não acontece todos os anos? }\end{array}$ \\
\hline Epistemologia da ciência & $\begin{array}{l}\text { Qual é o verdadeiro motivo da ciência? } \\
\text { Qual foi a lei mais importante que Newton criou? } \\
\text { Quem inventou a Física? }\end{array}$ \\
\hline Calor e Temperatura & $\begin{array}{l}\text { Porque, quando chove o calor aumenta? } \\
\text { Como fazer fogo com gravetos e pedras? } \\
\text { Porque quando ligamos o fogo e ao passar 3 minutos a água começa a } \\
\text { borbulhar? }\end{array}$ \\
\hline
\end{tabular}

Fonte: dos autores.

O relato explicitado pelo Pibidiano PHGM permite uma série de reflexões, por exemplo, ao mencionar "que outros subprojetos não realizam essa proposta da mesma forma". Assim, alimenta uma crítica às propostas (de pesquisa, ensino e extensão) que são desenvolvidas pela Universidade nas escolas sem a participação efetiva de professores no planejamento das ações ou, ainda, que não trazem devolutiva às escolas. Ao mencionar a opção por aulas "[...] em contraturno os graduandos se veem em uma posição não tão realista quanto a que o subprojeto Física proporciona, pois trabalhamos em salas reais", o licenciando chama a atenção para a importância de vivências no cotidiano das salas de aula, em oposição aos cursos previamente moldados em contraturnos, nos quais em muitos casos pautam-se por ações controladas e escolhas sobre quem irá participar das ações, maquiando muitas vezes a realidade escolar, em âmbito da educação brasileira. Neste contexto as menções "salas reais", "escolher para quais alunos daremos aula" e "lidar com diversos tipos de alunos" referem-se ao cotidiano imediato enfrentado pelos professores no dia-a-dia escolar o que, na visão do pibidiano, é uma experiência essencial para os professores em formação. Constatações como esta evidenciam a importância do programa PIBID na formação de professores.

Ademais, os licenciandos construíram aulas com diferentes instrumentos pedagógicos, tais como apresentações em projeção multimídia (Power Point), vídeos e experimentos reais e virtuais, com o intuito de facilitarem a intervenção em sala de aula. Optamos por utilizar instrumentos pedagógicos variados por considerarmos que contribuem para o processo de ensino e aprendizagem, principalmente quando conectados à tecnologia presente na vida do jovem estudante de Ensino Médio. 
Cada licenciando ficou responsável por desenvolver as atividades em uma sala, encaminhar as dúvidas e construir as aulas, com posterior retorno à sala, sempre acompanhados pela professora supervisora, o que os insere centralmente nas aprendizagens da docência. Entendemos que o fato de assumir a construção da aula e desenvolver as atividades com as turmas é de suma importância para a formação do pibidiano enquanto futuro professor (Oliveira \& Algebaile, 2019). Este fato vai ao encontro das perspectivas de formação docente que consideram que o contato com a sala de aula construída exclusivamente com a experiência dos estágios supervisionados pode ser um fator limitante para a atuação futura destes profissionais. Essa inserção em sala de aula, por meio de projetos ofertados pelas universidades, contribui com a formação inicial dos professores, fato também por eles evidenciado:

Vejo o programa PIBID muito enriquecedor para a formação do professor, uma vez que ele auxilia o aluno de graduação a ter seus primeiros contatos com a sala de aula e como comportar diante de uma situação dessa. E no crescimento pessoal é notável como modifica olhar de cada pessoa, pois quando você é colocado em uma situação que até então é desconhecida, você aprende a ter novas perspectivas, um novo olhar, atentar para coisas que nunca imaginaria que fosse importante no processo de ensino e aprendizagem [...] (Pibidiana LMPL, grifos nossos).

Dentre as várias intervenções didáticas realizadas, destaca-se aquela relacionada à temática "Evolução Estelar" (que engloba o nascimento, o desenvolvimento e a morte das Estrelas e Buracos Negros). Esta aula nitidamente despertou o interesse dos estudantes e gerou grande número de questionamentos, a exemplo de: Como se forma uma nebulosa? Como se formaram as estrelas? De que tamanho são as estrelas? Qual é a maior estrela conhecida pelo homem? O Sol vai explodir? O que aconteceria se o Sol explodisse? O que é um buraco de minhoca? Por que o Sol vai explodir? O que acontece se um buraco negro maior que o Sol puxasse o sistema? Buscando auxiliar as discussões sobre os assuntos levantados, foram utilizados dois vídeos ${ }^{1, \underline{2}}$ e posteriormente discutidas as características do Sol.

Além das contribuições para os bolsistas, percebemos grande empenho dos jovens do ensino médio em participar das atividades propostas, o que permite inferir o impacto social da ação. Para os pibidianos, houve contribuições em sua formação inicial, pois a atividade proporcionou experiências da sala de aula que são vivenciadas no momento do estágio ou que podem vir a acontecer quando atuarem como professores responsáveis pela turma. No que tange às contribuições para a supervisora, as intervenções do PIBID Ihe proporcionaram realizar atividades que há muito tempo planejava, mas que devido à intensa carga horária de trabalho, não conseguia colocar em prática, além de aproximá-la de um contato constante com abordagens de viés mais inovador. Para os professores da universidade, houve a possibilidade de estreitar e cristalizar a integração com a Educação Básica, pensando a universidade como um continuum desta etapa, fato desejável em âmbito extensionista.

Neste sentido, o "Pílula da ciência: o conhecimento está no ar!" pode ser interpretado como via de trocas múltiplas, em que se aprende e se ensina simultaneamente. A experiência da supervisora, professora da escola, fomenta e norteia as ações dos pibidianos, sendo que as aspirações e motivações destes promovem novos olhares para o contexto escolar. O trabalho na escola ganha novos contornos, trazidos pelos licenciandos, que auxiliam a supervisora a rever repertórios e a buscar novas práticas que talvez tenham se perdido no processo de ensinar e aprender. Ela, em uma via de mão dupla, inseriu os licenciandos em práticas na cultura escolar, e possibilitou diálogo intenso e profícuo com a escola, ao orientá-los na leitura desta instituição.

O PIBID, enquanto ação de natureza também extensionista, é palco privilegiado para a promoção de práticas de ensino inovadoras e interdisciplinares, que poderão vir a complementar a formação de todos os envolvidos como professores em efetivo exercício, licenciandos em formação inicial, estudantes da educação básica e 
professores formadores, os quais se deparam com diferentes possibilidades educacionais, em uma perspectiva interprofissional.

\section{Breves Considerações}

Em consonância com o exposto, as atividades desenvolvidas com os estudantes não se restringiram à inserção e discussão conteudistas, mas ampliaram-se para as formas e os métodos empregados para que inovações pudessem ser efetivadas, com a participação central da professora e dos estudantes, como abordagem argumentativa dos conteúdos levantados pelos alunos e a adoção da abordagem de sala de aula invertida, em conformidade com parte dos aportes teóricos expressos na Introdução. Assim, neste movimento de integração escola-universidade, no contato com situações e com a dinâmica real da Educação Básica Pública, a escola contribui em grande medida para a formação dos licenciandos, particularmente daqueles participantes do PIBID, como indicado pelas falas dos pibidianos que subsidiam este artigo.

No intuito de promover a inovação metodológica, para além da discussão de conteúdos, preocupamo-nos com a abordagem utilizada e com o preparo dos pibidianos que iriam desenvolver a atividade, elementos estes também presentes em suas falas. Assim, tanto a fase de construção dos dados como a de retorno às salas de aulas com os estudantes propiciaram o repensar das ações docentes e discentes, tendo participação efetiva de todos os envolvidos, bem como ambiente agradável e construtivo para os processos de ensino e aprendizagem, dentro do ciclo planejamento, ação e avaliação presentes na pesquisa-ação.

O interesse dos estudantes talvez se justifique devido à temática que se destacou, a Astronomia, e também pela aproximação dos licenciandos com estes jovens da Educação Básica. Os pibidianos construíram experiências e aprendizados significativos ao conduzirem a atividade, afastando-se de abordagens tradicionais. Desta forma, o "Pílula da ciência: o conhecimento está no ar" possibilitou ouvir as inquietações dos estudantes do ensino médio, (re)pensar o trabalho docente em sala de aula, e aproximar os licenciandos de seu futuro ambiente de trabalho. Tais fatores são essenciais, quando pensamos em uma educação de qualidade, e na qual todos se façam protagonistas na construção do conhecimento, um pressuposto também visado pela extensão universitária.

\section{Agradecimentos}

Agradecemos à Coordenação de Aperfeiçoamento de Pessoal de Nível Superior (CAPES) pelo apoio financeiro aos bolsistas de Iniciação à Docência, supervisores e coordenadores de área, e pela gestão do Programa Institucional de Bolsa de Iniciação à Docência (PIBID) no âmbito da Universidade Federal do Triângulo Mineiro (UFTM). Em especial, agradecemos a professora Jane Magali pela contribuição na revisão ortográfica do texto.

\section{Contribuições de cada autor}

O autor P.D.C.J. foi o professor coordenador do PIBID-Física, responsável pela coordenação e orientação da equipe de pibidianos, bem como pela escrita de Resultados e Discussões e das Considerações Finais. A autora S.E.A. foi a professora-supervisora junto à EEFCX e contribuiu com a escrita do relato da experiência e com a condução das atividades na escola. O autor D.F.B.O. foi colaborador do projeto, redigiu a parte teórica e estruturou a versão final deste texto. 


\section{Notas}

1. Buraco Negro. Disponível em https://www.youtube.com/watch?v=ThG5RHBR7dA\&t=4s

2. Escala do Universo, comparação de tamanhos dos planetas e estrelas. Disponível em: https://www.youtube.com/watch?v=Y7hGC9PaXQk\&t=193s

\section{Referências}

Alffonso, C. M. (2019). Práticas inovadoras no ensino de ciências e biologia: diversidade na adversidade. Revista Formação e Prática Docente, 2, 69-85.

Araújo, M. F. F., \& Pedrosa, M. A. (2014). Ensinar ciências na perspectiva da sustentabilidade: Barreiras e dificuldades reveladas por professores de biologia em formação. Educar em Revista, 52, 305-318.

Arruda, S. J., \& Caetano, M. R. (2012). Inovação curricular na escola pública: a teoria e a prática de Projeto Salasambiente. Universo Acadêmico, 5(1), 111-126.

Arruda, S. M., Passos, M. M., Piza, C. A. M., \& Felix, R. A. B. (2013). O aprendizado científico no cotidiano. Ciência \& Educação (Bauru), 19(2), 481-498.

Azevedo, M. N. \& Abib, M. L. V. S. (2013). Pesquisa-ação e a elaboração de saberes docentes em ciências. Investigações em Ensino de Ciências, 18(1), 55-75.

Braga, J. C. F., \& Martins, A. C. S. (2019). When teacher education goes mobile: A study on complex emergence. Revista Brasileira de Linguística Aplicada 20(2), 353-381.

Campos, B. S., Fernandes, S. A., Ragni, A. C. P. B., \& Souza, N. F. (2012). Física para crianças: Abordando conceitos físicos a partir de situações-problema. Revista Brasileira de Ensino de Física, 34(1), 1402-1401.

Colombo Junior, P. D., \& Ovigli, D. F. B. (2018). A interface arte-ciência-cultura como forma de inovar a formação inicial de professores de Física. Revista Iberoamericana de Educación, 77, 97-120.

Colombo Junior, P. D., Alves, S. E., \& Santos, R. A. F. (2020). Abordagens colaborativas e o ensino de ciências por investigação na Educação Básica. In W. Faleiro, A. Viveiro, \& M. P., Assis (Eds.), Coleção Ensino de Ciências e Formação de Professores. (pp. 205-232). Goiânia: Kelps. Recuperado de https://www.kelps.com.br/wp-content/ uploads/2020/03/inovacao-letramento ebook.pdf

Correia, K. (2016). Projetos de Letramento no Ensino Médio: Novas perspectivas e desafios. Educação \& Realidade, 41(1), 259-277.

Dias, G., Nascimento, C., Souza Filho, J., Oliveira, C., \& Vayne Justino Alves, N. (2018). Projeto escolas na Universidade Estadual de Maringá: Criação de um ambiente de experimentação e exploração em ciências. Extensio: Revista Eletrônica de Extensão, 15(28), 193-202.

Dorigo, A., Anjos, A., Marcato, A. C., Pires, D., Gonçalves, L., Anholeto, L., ... \& Mello, D. (2020). Projeto Primeiros Passos na Ciência: Rompendo barreiras sociais e estreitando laços entre a comunidade acadêmica e o Ensino Médio público. Revista Brasileira de Extensão Universitária, 11(1), 47-59.

Fernandes, C. P., Monzambani, B. A., Benedetti-Filho, E., Santos Júnior, J. B., \& Cavagis, A. D. M. (2014). PIBID: Um canal de extensão universitária para o ensino de ciências. Revista Cidadania em ação - Extensão e Cultura 8(2), $100-112$.

Fernandes, C. S., Marques, C. A., \& Delizoicov, D. (2016). Contextualização na formação inicial de professores de ciências e a perspectiva educacional de Paulo Freire. Ensaio Pesquisa em Educação em Ciências, 18(2), 9-28.

Ferreira, M. V., Muenchen, C., \& Auler, D. (2019). Desafios e potencialidades em intervenções curriculares na perspectiva da abordagem temática. Ensaio Pesquisa em Educação em Ciências, 21, e10499.

Fórum de Pró-Reitores de Extensão das Universidades Públicas Brasileiras (1987). Conceito de extensão, institucionalização e financiamento. Criação do Fórum de Pró-Reitores de Extensão das Universidades Públicas Brasileiras. Brasília: FORPROEX. Recuperado de https://www.ufmg.br/proex/renex/images/documentos/1987-IEncontro-Nacional-do-FORPROEX.pdf 
Fórum de Pró-Reitores de Extensão das Universidades Públicas Brasileiras (2012). Plano Nacional de Extensão Universitária. Encontro de Pró-Reitores de Extensão das Universidades Públicas do Brasil. Manaus: FORPROEX. Recuperado de https://www.ufmg.br/proex/renex/images/documentos/2012-XXXII-Encontro-Nacional-Brasilia.pdf

Fragelli, R. R. \& Mendes, F. M. (2012). “Onde está Osama?” - Um Jogo Educativo na Área de Física. Participação, 20, 815.

Freire, P. (1996). Pedagogia da Autonomia: Saberes necessários à prática educativa. São Paulo: Paz e Terra.

Gonçalves, B., Vicentini, M. A., de Paula, K. A. M. R., de Assis Ferraz, J., Nascimento, G. A. C., Cordovil, B. L., \& de Oliveira, J. B. (2015). 'PET- Física vai à escola' - uma metodologia para despertar o interesse no estudo de ciências em alunos de ensino básico. Revista Ciência em Extensão, 11(1), 32-45.

Oliveira, F. C. P., \& Algebaile, E. B. (2019). As contribuições do PIBID para uma formação crítica e social do professor: a experiência da Universidade Regional do Cariri (Urca). Revista Brasileira de Estudos Pedagógicos, 100(256), 612-632. Recuperado de https://doi.org/10.24109/2176-6681.rbep.100i256.4165

Oliveira, W. D., \& Benite, A. M. C. (2015). Aulas de ciências para surdos: estudos sobre a produção do discurso de intérpretes de LIBRAS e professores de ciências. Ciência \& Educação (Bauru), 21(2), 457-472.

Pereira, E. M. A, Carneiro, A. M., \& Gonçalves, M. L. (2015). Inovação e avaliação na cultura do ensino superior brasileiro: formação geral interdisciplinar. Avaliação: Revista da Avaliação da Educação Superior (Campinas), 20 (3), 717-739.

Pessoa, G. P., \& Costa, F. de. (2019). A Flipped Classroom no ensino de Ciências e Biologia: Uma articulação com o ensino de Ciências por investigação. Tecnia, 4(2), 208-225.

Pietrocola, M. (2005). Construção e realidade: O papel do conhecimento físico no entendimento do mundo. In: Ensino de Física - conteúdo, metodologia e epistemologia em uma concepção integradora. Florianópolis: UFSC.

Silva, L. V., \& Bego, A. M. (2018). Levantamento Bibliográfico sobre Educação Especial e Ensino de Ciências no Brasil. Revista Brasileira de Educação Especial, 24(3), 343-358.

Solino, A. P., \& Sasseron, L. H. (2019). A significação do problema didático a partir de potenciais problemas significadores: análise de uma aula investigativa. Ciência \& Educação (Bauru), 25(3), 569-587.

Taxini, C. L., Puga, C. C. I., Silva, C. S. F., \& Oliveira, R. R. (2012). Proposta de uma sequência didática para o ensino do tema "estações do ano" no ensino fundamental. Ensaio Pesquisa em Educação em Ciências (Belo Horizonte), 14(1), 8197.

Trindade, J. I. S., Souto, L. L., \& Santos, D. P. (2013). PIBID Um programa de extensão universitária fortalecedor do processo ensino aprendizagem de Geografia da Escola Municipal Jair de Oliveira Montes - Claros/MG. (1-16). Anais do Encuentro de Geógrafos de América Latina, Lima, Peru. Recuperado de https://is.gd/BTGXMe

Ustra, S. R. V., Lopes, J. P., Tavares, O. A., Ustra, M. K. (2014). Entrelaçando espaços para a Física no Ensino Fundamental. Cataventos - Revista de Extensão da Universidade de Cruz Alta, 6(1), 27-39.

Vieira, S., \& Sabbatini, M. (2017). Construção do conhecimento contextualizado e cultura popular no ensino de ciências através da produção de vídeos digitais no contexto da folkcomunicação científica e tecnológica. Revista de Cultura e Extensão USP, 17(supl.), 51-62.

Watkins, J. \& Mazur, E., (2010). Just-in-time teaching and peer instruction. In S. Simkins \& M. Maier (Eds.), Just-in-Time teaching: Across the disciplines, across the academy, (pp. 39-62). Sterling: Stylus.

Zompero, A. F., Gonçalves, C. E. S., \& Laburú, C. E. (2017). Atividades de investigação na disciplina de Ciências e desenvolvimento de habilidades cognitivas relacionadas a funções executivas. Ciência \& Educação (Bauru), 23(2), 419436.

\section{Como citar este artigo:}

Colombo Junior, P. D., Ovigli, D. F. B., \& Alves, S. E. (2020). Iniciação à docência em Física e as indagações de estudantes da educação básica - um relato. Revista Brasileira de Extensão Universitária, 11(3), 288-300. https://periodicos.uffs.edu.br/index.php/RBEU/ article/view/11597/pdf 